\title{
'Disrupting' Legal Education and Producing 'Bizarre' Lawyers? Intensifying Law Students' Motivation and Learning Concentration via Gamified Augmented Reality Experience
}

\author{
Shahrul Mizan Ismail
}

\begin{abstract}
Despite the rapid evolution of technology that is dramatically changing higher learning education, many law instructors still seem hesitant to incorporate them into their pedagogical approaches. Perhaps the reason lies behind the fear of losing all the traditional benefits of conventional physical interactions in class. But what if students' motivation and learning concentration can be enhanced using this technology? What if gamifying the class, and using augmented reality technology can stimulate motivation, concentration and collaboration in learning? This paper aims to explore the effects of using a gamified augmented reality experience in intensifying law students' motivation to learn, and their comprehension of the law. The paper discusses the issue in four aspects, namely, the origin and background of gamification and augmented reality in higher learning education, the usage of gamification and augmented reality in law schools worldwide, the implementation of the same by the author in his own civil procedure class in UKM, and his observations of students' motivation and concentration based on the approach taken. Using both quantitative and qualitative approach, the paper showcases and shares the author's experience in implementing the method in his class, and investigates the benefits and drawbacks of adopting the approach.
\end{abstract}

Keywords: Law students, gamification, augmented reality, transformative education, quantitative

\section{INTRODUCTION}

When receiving a case, especially when it is involve complex scenario with twisting plot, there is a lot of information that it is hard to assimilate. Facts about the case, how the case occurred, and even small details require particular observation, and a visual representation can help to improve the courts' perception. In the world where the technology plays important roles in every aspect of life, it also can be used in teaching and learning in law schools. By using technology, lawyering skills can be improve without leaving traditional method of civil procedure.

The evolution of new technologies in wireless communication systems as well as hardware and software for mobile devices has often enabled new opportunities for education. Since learners have constant exposure to a variety of immersive technologies, the role of the educational process becomes more challenging. Besides that, effective feedback and fastest assessment during the learning process are required, as well as the ability for learners to work at

Revised Manuscript Received on November 11, 2019.

ShahrulMizan Ismail, Assoc. Prof. Dr. ShahrulMizan Ismail, National University of Malaysia their own pace, without losing the element of interactivity and personalized education. Higher education institutions must transform their teaching learning process and approaches to change how they engage with their students, innovate around new techniques and models and re-think how they operate (Moreira et al., 2017). The use of such technologies stimulates the learning environments and boost student achievement. The capabilities of mobile devices have led to the emergence of technologies that have opened up new possibilities in the teaching and learning processes, namely Gamification and Augmented Reality (AR).

\section{OBJECTIVE}

To examine the issue in four angles, in particular, the source and foundation of gamification and expanded reality in higher learning training, the use of gamification and enlarged reality in graduate schools around the world, the execution of the equivalent by the creator in his own common technique class in UKM, and his perceptions of understudies' inspiration and fixation dependent on the methodology taken. The paper additionally grandstands and offers the creator's involvement with executing the technique in his group, and examines the advantages and disadvantages of embracing the methodology.

\section{LITERATURE REVIEW}

Gamification is depicted as 'utilizing game-based mechanics, style and game intuition to connect with individuals, rouse activity, and advance learning' (Kapp, 2012). In an instructive setting, O'Donovan et al., (2013) ordered gamification as an instructional technique, particularly as for the legitimacy of its mix. Game-based learning includes the consolidation of games into exercise, where the chief point is to expand understudies' commitment and inspiration. Writing detailed that few game plan components were utilized broadly in the instructive and learning settings, including focuses, level or stages, identifications, pioneer sheets, prizes or rewards, progress bars, storyline, and criticism (Pechenkinaet al., 2017). With regards to the instructing learning process, the utilization of gamification has had a positive outcome, especially in the execution in a lot of topics and in a few age gatherings, from undergrad to college level (Kapp, 2012). Furthermore, gamification may improve learning by defeating some learning boundaries, for example, absence of consideration, inclusion and premium, presented the joy factor in performing undertakings, or learning exercises 
(Ainley\&Ainley, 2011). Various scientists have distinguished Augmented Reality (AR) as having the capacity to improve learning and educating. The expression "Increased Reality" was presented by Caundell and Mizell (1992) in the mid 1990s. AR signifies 'any innovation equipped for consolidating genuine and virtual data in a significant manner to give a mixed learning experience that advances reality with computerized innovation' (Caundell\&Mizell, 1992). Different analysts characterized AR by the execution of three criteria: (a) the mix of virtual and genuine conditions, (b) which making some genuine memories collaboration and (c) 3D reference (Azuma, 1997). The least difficult meaning of $A R$ is an innovation which permits PC created virtual symbolism to precisely overlay physical items continuously (Zhou et al., 2008). In contrast to Virtual Reality (VR), which totally drenches the client's faculties in an engineered domain, AR allows the client to see this present reality through a virtual overlay. To explain this, Milgram and Kishino (1994) proposed the Reality-Virtuality (VR) Continuum). As shown in Figure 1, the first one is what we are all familiar with, real environment or real world. The opposite end of the scale is virtual environment, where all information perceived by the user is computer-generated. In the middle, between these two, there have two types of augmented environments: Augmented Reality (AR) which takes the real environments as its backdrop and overlay with computer-generated content, and Augmented Virtuality (AV), in which a computer-generated world serves as the backdrop and superimposed by real-world data (Milgram et al., 1994). Virtual objects used in AR systems may include text, still images, video clips, sounds, 3D models and animations. Ideally, these virtual objects will be perceived as coexisting within a real-world environment (Bower et al., 2014). Other than that, AR enable to drive the player interaction and learning through gamified stories or narratives. These augmentations can serve to aid and enhance individuals' knowledge and understanding of what is going on around them. Thus, AR can be seen as a conduit for bringing together education in virtual environments and the real world.

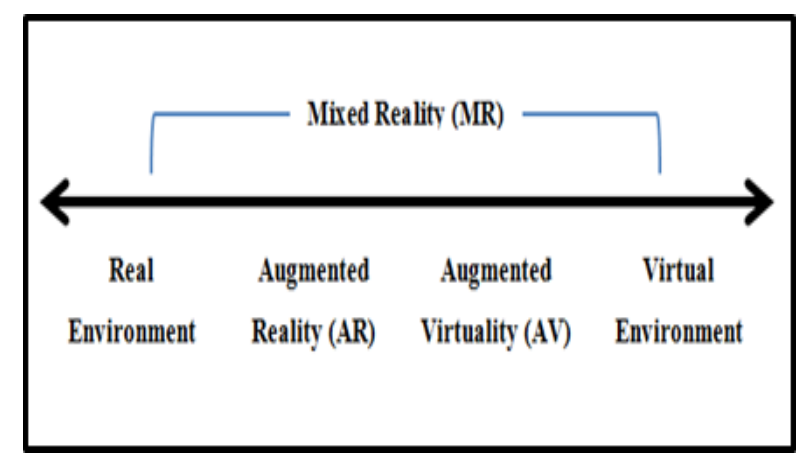

Figure 1. Reality-Virtuality (VR) Continuum

Source: Milgram, P., \&Kishino, F. (1994). A Taxonomy of Mixed Reality Visual Displays.

IEICE Transactions on Information Systems, 77(12).

A few instructive employments of this AR have just been archived in the writing. For example, AR has been utilized to build up understudies' comprehension of science, including natural science (Hsiao et al., 2011, Squire \&Klopfer 2007), microbiology (Chen, 2006) and biomedical science (Dunleavy et al., 2009). The situation based
"Outsider Contact!" reproduction has been utilized to create numerical reasoning aptitudes (Mitchell, 2011). Gamification and pretend based AR has been applied to upgrade inspiration and a feeling of legitimacy in therapeutic science (Rosenbaum et al., 2007)

\section{IV. .METHODOLOGY}

The survey was given to 114 students that were involved in gamification and game based learning in law classrooms. Gamification and game based learning were done using online and offline software such as Mentimeter, Quizlet, Socrative, HP Reveal, BlippAR and Unity3D/Vuforia. The software were prepared before the law classrooms began.

\section{FINDING AND DISCUSSION}

Finding of a survey made with 114 fourth year law students in 2018:

How Effective is Learning Law Subject through Gamification \& Game-Based Learning

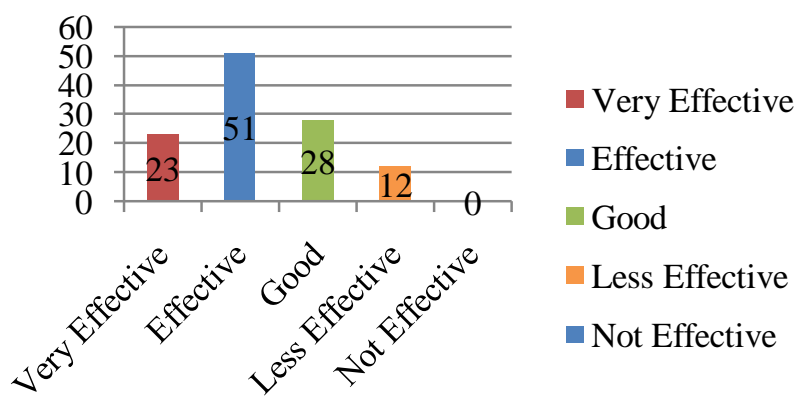

Chart 1: Response from the students expressing their opinion on how effective is learning law subject through gamification\& game-based learning.

Chart 1 show how students responded toward the effectiveness of learning law subject through gamification and game-based learning. Half of them were graded the proposed teaching method as effective, while 23 students were graded the technique as very effective. These groups of student are able to responds in active way toward their lecturer. Besides that, 28 students were moderately agreed with the effectiveness of the gamification\& game-based learning methods, while 12 students were think that the proposed teaching method are less effective compare to the existing learning methods. 
How Do You Rate Your Participation During Gamification \& Game-Based Learning Session in Class

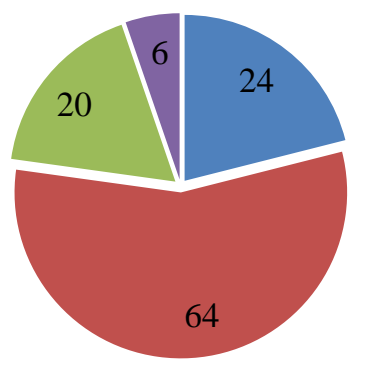

Very Active

Active

Normal

- Passive

Chart 2: Response from the student showing how they rate their level of participation in class during Gamification\& Game-Based Learning sessions

As shown in Chart 2, more than half of the students were rated their level of participation on class during gamification\& game-based learning sessions as active, while 24 students were rated their level of participation as very active. From these score, we may estimate the level of their interest towards the implementation of this new teaching and learning technique, as they can participate in good way. 20 students were believes that they will act as normal, which is not too active and not to passive when lecturers used this gamification\& game-based learning technique in the class. Conversely, there had a small number of students who opposed to participate actively on class during

\section{Whether I Understand the Lesson More \\ Effectively when The Lecturer Uses \\ Gamification \& Game-Based Learning \\ Methods}

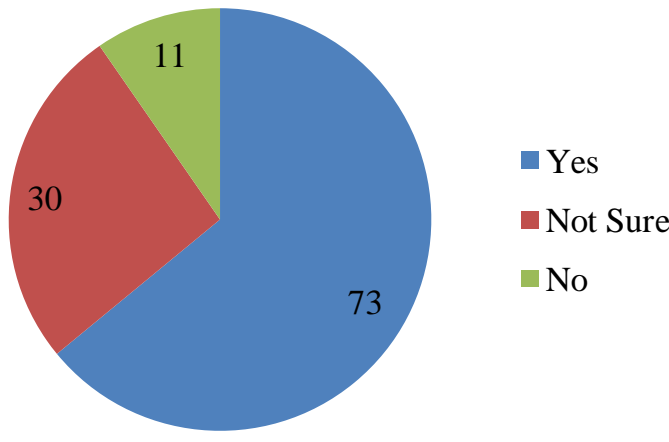

Chart 3: Response from the student showing whether they understand the lesson more effectively when it is conducted through Gamification\& Game-Based Learning methods In this section, the students were asked about their understanding towards the lesson that conducted through gamification\& game-based learning methods. As shown in Chart 3, 73 out of 114 students will understand the lesson better when the teaching and learning process were conducted through gamification\& game-based learning methods. We believed that they can respond well in the class. On the other hand, 30 students were not sure about their understanding, while 11 students still believed that their understanding will not enhanced or affected by the implementation of the proposed methods. Although these numbers quite high, as an instructors, it always be our responsibilities to create an exciting learning environment in class.

Whether I am More Active in Class and

Participated in Class Activities when The Lecturer Uses Gamification \& GameBased Learning Methods

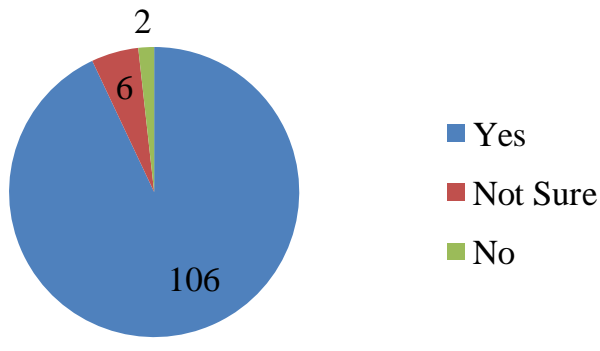

Chart 4: Response from the student showing whether they become more active in class and participates in class activities when the class is conducted through Gamification\& Game-Based Learning methods

As illustrated in Chart 4, majority of the students, which is 106 out of 114 students, will participate actively in class activities when the class is conducted through gamification\& game-based learning methods. From this number, we assumed that the implementation of the learning methods can help in enhancing students' interest as well as attention towards the lessons. On the other hand, there was a few numbers of students which think that they are not being able to participate actively when the class is conducted through gamification\& game-based learning methods. This might be comes from lack of understanding about how the methods operating or applying into the class.

Whether the Class Conducted Using Gamification \& Game-Based Learning Methods Enhances Your Communication Skills, Teamwork, Critical-Thinking Skills \& Endurance

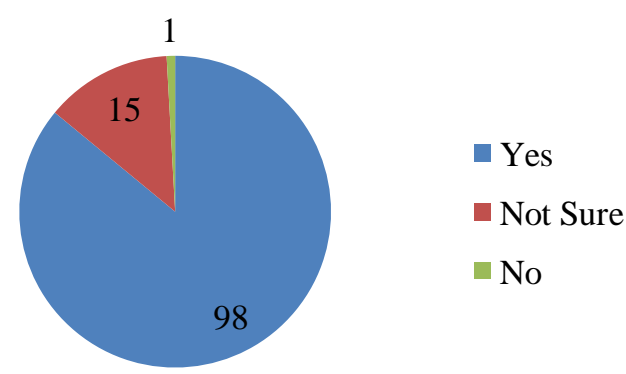

Chart 5: Response from students showing whether Gamification\& Game-Based Learning methods enhance their communication skills, teamwork, critical thinking skills and endurance. 
The purpose of the application of gamification and gamebased learning methods is to enhance students' communication skills, teamwork, critical thinking skills and endurance. From the survey, 98 out of 114 students agreed that the implementation of these methods in class during teaching process will improve their learning performance. On the other hand, as shown in Chart 5, only one student who not agreed with, while the others were not sure about how far this method can help in enhancing their learning performance.

How Many Weeks Do You Want the

Class to be Conducted Using

Gamification \& Game-Based Learning Methodology

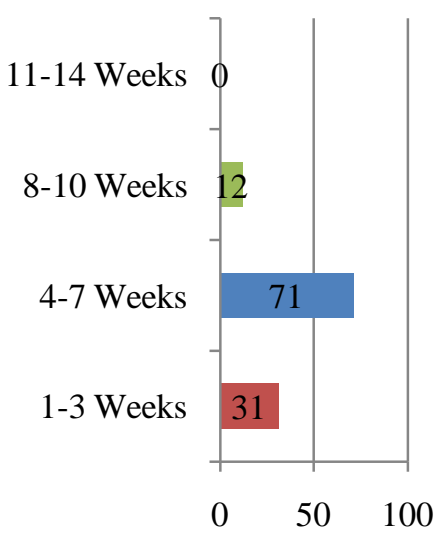

Chart 6: Response from students showing, out of 14-week per semester, how many weeks do they want the class to be conducted using Gamification\& Game-Based Learning methods in class.

This section discussed about how frequent the class will be conducted using gamification and game-based learning methods in class, based on students' opinion. As illustrated in Chart 6, most of the students voted for 4-7 weeks, 31 students voted for 1-3 weeks, and 12 students chose for 8-10 weeks. From these results, we assumed that students were very satisfied if the gamification and game-based learning were used moderately in course of semester.

\section{CONCLUSION}

As a conclusion, gamified augmented reality will provide better learning experiences and motivate students to focus in law classes. This enhanced technology making law courses becoming more interactive, higher rate of understanding and students participating in classes.

\section{ACKNOWLEDGEMENT}

The author would like to thank and acknowledge that this is research is supported by Centre for Research and Instrumentation Management (CRIM) UKM under Research Grant No. KRA-007-2017 entitled 'Incorporating Heutagogical and Peeragogical Components in Legal Education to 'Disrupt' Conventional Teaching Model: Developing Collaborative 'Mission-Impossible-MetPokemon-Go' Game via Physical, Virtual \& Augmented Reality Activities'.

\section{REFERENCES}

1.F. Moreira, N. Durao, C.S. Pereira, M.J. Ferreira, "Versatile Learning with Gamification and Augmented Reality in Portuguese High Education," In Proceedings of EDULEARN17 Conference, pp. 4263 4270, 2018

2.K. Kapp, "The Gamification of Learning and Instruction: Game-Based Methods and Strategies for Training and Education," John Wiley and Sons, 2010

3.S. O'Donovan, J. Addition, P. Marais, "A Case Study in the Gamification of a University-level Games Development Course," In Proceedings of the South African Institute for ComputerScientists and Information Technologists Conference, pp. 242-240, 2013

4.Pechenkina, E., Laurence, D., Oates, G., Eldridge, A. and Hunter, D. Utilizing a gamified portable application to expand understudy commitment, maintenance and scholastic accomplishment.

5.M. Ainley, J. Ainley, "A social point of view on the structure of understudy enthusiasm for science," International Journal of Science Education, vol. 33, no. 1, pp. 50-75, 2009

6.T. Caudell, D. Mizell, "Increased reality: A use of heads-up show innovation to manual assembling forms," In Proceedings of the Twentyfifth Hawaii InternationalConference on, no. 2, pp. 660-670, 1993.

7.R. Azuma, "A Survey of expanded reality," Presence, vol. 6, no. 4, pp. 355-390, 1997

8.M. Grove, C. Howe, N. McCredie, A. Robinson, D. Grover, "Enlarged Reality in instruction cases, spots, and possibilities," Educational Media International.

9.Hsiao, K.- F., Chen, N.- S., and Huang, S.- Y. (2011). Learning while at the same time practicing for science instruction in enlarged reality among young people. Intelligent Learning Environments, 20, 330-350

10.Squire, K., \&Klopfer, E. (2007). Increased reality reproductions on handheld PCs. Diary of the Learning Sciences, 16, 375-415.

11.Chen, Y.- C. (2006). An investigation of looking at the utilization of enlarged reality and physical models in science instruction. In Proceedings of the 2008 International Conference on Virtual Reality Continuum and its Applications, Hong Kong, China: ACM.

12.Rasimah, C., Ahmad, A., \&Zaman, H. (2011). Assessment of client acknowledgment of blended reality innovation. Australasian Journal of Educational Technology, 27, 1370-1387.

13.Dunleavy, M., Dede, C., and Mitchell, R. (2009). Affordances and constraints of vivid participatory enlarged reality reenactments for educating and learning. Diary of Science Education and Technology, 18, 17-25.

14.Mitchell, R. (2011). Outsider Contact! Investigating instructor execution of an enlarged reality curricular unit. Diary of Computers in Mathematics and Science Teaching, 30, 270-300.

15.Rosenbaum, E., Klopfer, E. and Perry, J. (2007). On area learning: Authentic applied science with organized increased substances. Diary of Science Education and Technology, 16, 30-46.

16.Zhou, F., Duh, H.- L., and Billinghurst, M. (2008). Patterns in increased reality traching, collaboration and show: A survey of ten years in ISMAR. Blended and Augmented Reality, ISMAR seventh IEE/ACM International Symposium pp. 195-200. Cambridge: IEEE.

17.Milgram, P., and Kishino, F. (1994). A scientific classification of blended reality visual showcases. IEICE Transactions on Information Systems, 80(12).

18.Milgram, P., Takemura, H., Utsumi, An., and Kishino, F. (1994) Increased reality: A class of showcases on the truth virtuality continuum. Telemanipulator and Telepresence Technologies, 2351, 280-290.

\section{AUTHORS PROFILE}

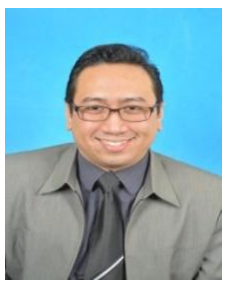

Assoc. Prof. Dr. ShahrulMizan Ismail Associate Professor, Faculty of Law (FUU), National University of Malaysia (UKM), Malaysia (2016 Present)

Area of specialization:

(1) International Human Rights Law;

(2) International Criminal Justice \& Armed Conflict);

(3) Civil Procedure;

(4) Legal Education

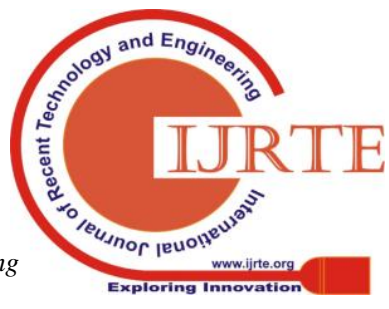

